\title{
La vacunación en la farmacia comunitaria: una oportunidad para el sistema sanitario
}

\author{
Maricarmen Magro \\ Farmacéutica coordinadora del grupo de Inmunología de SEFAC.
}

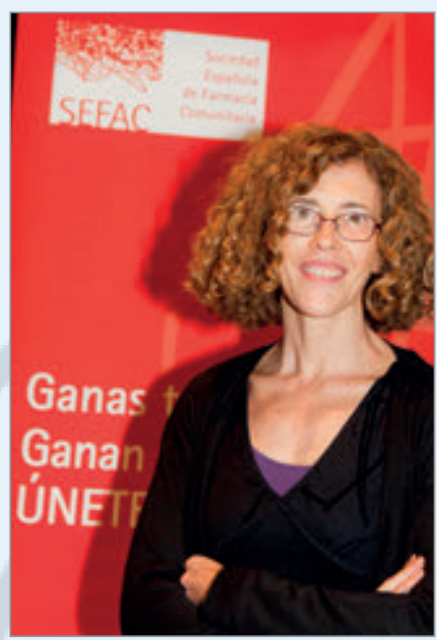

Maricarmen Magro
Cuando desarrollas tu carrera profesional en el ámbito de la farmacia familiar y comunitaria, pocos de nosotros damos la importancia que merecen a las vacunas como medicamentos que se dispensan en ella. No quiero decir con esto que falte rigor en aspectos como su correcta conservación y almacenamiento o no se preste especial atención en mantener la cadena de frío con el fin de asegurar que cuando sea administrada al paciente llegue en perfectas condiciones y resulte efectiva. Pero, ¿realizamos una dispensación igual que si se tratara de otros medicamentos con los que estamos más familiarizados por tratar enfermedades crónicas o más prevalentes? Me atrevería a asegurar que no. Nos limitamos a "entregar la vacuna", indicando al paciente que la conserve en el frigorífico (no congelador) hasta que se la pongan en un centro de salud público o privado, que no incluye actualmente a la farmacia comunitaria en España. ¿Realizamos una correcta educación sanitaria y le ofrecemos un seguimiento tras la vacunación? La respuesta vuelve a ser, en la mayoría de los casos, no. Nos centramos principalmente en informar sobre los posibles efectos adversos tras la vacunación. ¿Y la vacunación del viajero? Aquí se puede afirmar que sí estamos avanzando más en ofrecer asesoramiento. ¿Por qué actuamos así frente a este tipo de fármacos? Sencillamente, y desde mi particular punto de vista, porque nos falta formación. Creemos que esta rama de la sanidad no forma parte de nuestra actividad profesional y damos por hecho que es más competencia de salud pública, los centros de salud y enfermería que nuestra. Deberíamos plantearnos un cambio respecto a cómo abordar la vacunación desde la farmacia comunitaria.
Prevenir y evitar la enfermedad y alejar la muerte ha sido siempre un anhelo de los humanos y es el objetivo final de la política sanitaria. En España hasta hace poco, cuando comenzó el proceso de implantación y organización del Sistema Nacional de Salud en los años 80 del siglo pasado, había más inquietud social por disponer de un hospital cerca de nuestro domicilio que en prevenir con eficacia causas de muerte y discapacidad. Las vacunas solo eran importantes para la población infantil y no para la adulta (se creía que las infecciones en este grupo de población estaban controladas en España y Europa) (1).

En el campo de la vacunología, desde los años 80 hasta la actualidad es el periodo en el que más vacunas se han descubierto y mayores avances tecnológicos se han desarrollado, aunque aún no se disponga de vacunas efectivas contra la tuberculosis, malaria y VIH, enfermedades que concentran los mayores esfuerzos investigadores, y que la vacuna contra el virus del ébola aún esté en fase experimental. Se ha dotado a la vacunología de nuevos adjetivos (inversa, personalizada, predictiva, vaccinómica, etc.) y se ha visto un esfuerzo mundial por erradicar enfermedades como la polio. Nunca en la historia se habían alcanzado las coberturas vacunales de las que ahora disfrutan la mayoría de los países (1). Sobre este último punto me gustaría destacar un aspecto importante: la cobertura vacunal podría incrementarse si el Ministerio de Sanidad contara con la colaboración de la farmacia comunitaria. De hecho ya hay países como el Reino Unido, Portugal, EEUU, Puerto Rico, Nueva Zelanda, Canadá y Australia, que cuentan con las boticas para lograr este fin. 
Las vacunas y las campañas de vacunación han salvado un número incalculable de vidas. El papel de los organismos internacionales en la erradicación y prevención de las principales enfermedades infecciosas es un hecho constatado y objetivo. El importante valor social y económico que las vacunas poseen solo puede obtenerse si son utilizadas (1).

Sin embargo, una sombra enturbia esta realidad optimista sobre la vacunación. Se está empezando a detectar cierta desconfianza en la seguridad de las vacunas asociada al auge de internet y los grupos antivacunas, que tiene incidencia en la aceptabilidad de la vacunación. Aunque las vacunas son cada vez más seguras y eficaces, el efecto mediático de ciertas noticias ha amplificado la percepción de riesgo en grupos sensibles de población. Recordemos el caso de muerte por difteria del niño de 6 años de olot (Girona), que por decisión de los padres no fue vacunado frente a esta enfermedad. La vacunación en España no es obligatoria, sin embargo, tras este trágico suceso se planteó la obligatoriedad o no de la vacunación en nuestro país.

Otra vacuna que tampoco debemos olvidar mencionar es la vacuna frente a la varicela y las distintas etapas por las que ha pasado. Desde su dispensación en las farmacias comunitarias españolas para la inmunización en la población infantil con una 1 dosis a los 12-15 meses y otra entre los 2 y 3 años, hasta que dejara de comercializarse en las boticas en junio del 2013, dejando solo la vacunación a los 12 años de edad siguiendo el calendario común de vacunación. Este hecho provocó que los padres, haciendo caso a las recomendaciones de la Asociación Española de Pediatría de vacunar a sus hijos, viajaran a Portugal y Andorra donde sí estaba disponible en las boticas para comprarla. Posteriormente, en junio del 2014, el Ministerio de Sanidad, Servicios Sociales e Igualdad y la Agencia Española de Medicamentos y Productos Sanitarios decidieron que pasara a ser solo de "uso hospitalario" sin dar razones de salud pública que justificaran esta medida. A partir del año 2016, por decisión del Consejo Interterritorial del SNS, se ha levantado el bloqueo de esta vacuna que pasará a formar parte del calendario vacunal oficial en edad pediátrica para niños a partir de 1 año y estará financiada por el sistema público. Además mantendrá la vacunación en adolescentes a partir de 12 años que no hayan pasado la enfermedad. Otra vacuna sobe la que se ha hablado recientemente es la vacuna de la meningitis $\mathrm{B}$, que parece que sí podría dispensarse libremente en las farmacias en un futuro.

Con estas nuevas decisiones tomadas desde el Ministerio de Sanidad, nos acercamos a países con sistemas sanitarios avanzados en materia vacunal como EEUU, Canadá, Australia y Alemania, entre otros que anteriormente ya mencioné.

En el libro Presente y futuro de la vacunología. 11 reflexiones imprescindibles cuyos directores son dos expertos en este campo, José Luis Puerta y Ángel Gil de Miguel (1), se habla del concepto de "vacunología social" como la necesidad de armonizar la vacunología como ciencia con la vacunología como servicio social, entendiendo el hecho de que se necesita algo más que una serie de descubrimientos para extender los beneficios de la ciencia. Explicar, debatir, persuadir y comunicar desde la evidencia científica es un reto añadido que precisa la vacunología.

¿Qué podemos decir sobre la vacunación en el adulto? Desde mi punto de vista, el farmacéutico comunitario puede jugar un importante e imprescindible papel debido a las propias características de este grupo de población.
Una noticia reciente de Europa Press habla de que la Sociedad Española de Geriatría y Gerontología (SEGG) ha señalado la necesidad de crear un calendario de vacunación para adultos, dirigido especialmente a la prevención de enfermedades en personas mayores de 60 años. Desde la SEGG han destacado su apuesta por un calendario vacunal único, a nivel nacional y equitativo para todas las comunidades autónomas. Cada año se hace una campaña para favorecer la vacunación antigripal, en la que también se apuesta por la vacunación anti neumocócica. A medida que avanza la edad, el sistema inmune se va debilitando y aumentan las posibilidades de padecer una enfermedad crónica o contraer algunos tipos de infecciones prevenibles. Desde el Grupo de Vacunas de la SEGG recomiendan la vacunación sistemática de todos los mayores de 60 años frente a la gripe, el neumococo, la difteria, el tétanos, la tos ferina y el herpes zóster (2). ¿Por qué no colaborar desde SEFAC con sociedades científicas como ésta para ayudar a que ese objetivo se cumpla?

Como se puede deducir de todo esto, la importancia de la vacunación para la prevención de enfermedades tanto en la edad infantil como en la edad adulta es motivo de debate continuo y cada vez está más en los medios de comunicación, redes sociales e incluso en la propia población que exige más información que permita a los ciudadanos decidir si vacunar o no a sus hijos, o vacunarse ellos mismos.

Teniendo en cuenta que lo que al final se busca a nivel de salud pública es alcanzar mayor cobertura vacunal para erradicar enfermedades y que cuantos más organismos estemos implicados en participar más fácil será alcanzar esta meta, me pregunto: ¿Por qué no se podría desarrollar un servicio profesional farmacéutico de administración de vacunas en las farmacias comunitarias españolas?

Hay motivos suficientes para que la respuesta fuera "sí".

Somos agentes de la salud y por nuestras características de accesibilidad, proximidad a la población y profesionalidad, nuestros conocimientos y nuestra implicación en todo aquello relacionado con el medicamento pueden resultar beneficiosos tanto para el paciente como para el sistema sanitario.

La farmacia y el farmacéutico comunitario son aliados valiosos para optimizar recursos materiales y humanos en la consecución de una mayor cobertura vacunal. La red de farmacias comunitarias distribuidas uniformemente en toda la geografía española puede complementar la cobertura sanitaria de la población junto con los centros de salud.

La farmacia familiar y comunitaria dispone de personal sanitario facultativo para asumir las competencias necesarias. No requiere de previsión de un gran stock como ocurre en los centros de vacunación y tiene un sistema de distribución de medicamentos que permite en el mismo día poder reabastecerse en caso necesario de las vacunas necesarias. En otros países, los servicios de salud empiezan a contemplar a la farmacia como punto de administración de vacunas complementario a los centros de salud con resultados positivos que se traducen en un aumento de los índices de cobertura vacunal. En particular, se está trabajando en las campañas de vacunación de la gripe.

Estados Unidos lleva claramente la voz cantante en la vacunación desde farmacias, han sido pioneros y tienen programas muy avanzados, junto con Reino Unido y Canadá. Allí, junto con Puerto Rico o Portugal, se ha 
trascendido la campaña antigripal y las farmacias pueden vacunar contra el neumococo, varicela, tétanos, difteria, hepatitis (A y B), el virus del papiloma humano, anticonceptivas o la vacunación a viajeros internacionales, como la polio o la fiebre amarilla. La vacunación de la gripe se revela como el catalizador de este servicio en la farmacia comunitaria. Datos de países del entorno europeo, como sería el caso de Irlanda, ponen sobre la mesa que la inclusión de la farmacia permite llegar a un espectro de la población que no suele visitar los centros de salud y que, a menudo, se quedan fuera de los programas de vacunación. Así, durante la campaña de 2012/2013 las boticas irlandesas vacunaron a unos 19.000 pacientes y al año siguiente la cifra se duplicó. Lo importante, según el Consejo Regulador de Farmacia (PSI), organismo independiente, es que en la campaña 2013/2014 la mayoría de pacientes (85 por ciento) que se vacunaron en las boticas lo hacían por primera vez, a pesar de pertenecer a grupos de riesgo. Otro país donde está evolucionando favorablemente la vacunación es Australia, aunque empezó en sólo dos estados, "tras el cambio de la regulación, el resto se están adaptando rápido”, explica Charlie Benrimoj, experto en Atención Farmacéutica y profesor de la Universidad de Sidney. Precisamente uno de los argumentos planteados por la corporación que representa a los farmacéuticos comunitarios, el Pharmacy Guild, es que los índices de vacunación son dispares entre los que están por encima de los 65 años (el 79 por ciento se vacuna) y los menores de 65 con perfiles de riesgo, de los que sólo se vacunaría el 42 por ciento. Además, estaría el factor de cercanía en áreas rurales contra el que los centros de salud tienen que competir. El servicio mejoraría el nivel de participación ciudadana en las campañas de inmunización. Así lo concluye un estudio realizado con farmacias de Tennessee (Estados Unidos), donde un grupo reducido de farmacias consiguió aumentar la cuota de vacunación contra herpes zoster. Y la respuesta de los pacientes a la posibilidad de vacunarse en farmacias es masiva, según estudios en Reino Unido o Canadá. Allí, la primera campaña contra la gripe en la región de Ontario superó la expectativas del Gobierno, ya que las boticas vacunaron a 250.000 pacientes (el Gobierno esperaba 100.000). A esto se sumaría otro beneficio adicional que sería "el derivado del ahorro" al sistema, que en Estados Unidos y Reino Unido rondaría los cinco dólares por paciente con respecto a la vacunación en centros públicos. De hecho, fue una de las motivaciones del Gobierno francés en 2014, para promover el servicio y que todavía sigue sobre la mesa. Una vez que son las farmacias las que vacunan, los centros de salud ya no tienen que hacer grandes aprovisionamientos y el control de los productos es más eficiente en las farmacias. La retribución por dicho servicio, dependiendo del país y las características del paciente, lo asume el propio paciente o el servicio de salud pública (3).

En España, de acuerdo con los datos del Ministerio de Sanidad, Servicios Sociales e Igualdad, la cobertura vacunal frente a la gripe en la población mayor o igual de 65 años la temporada del 2014/2015 fue del 56,2\%, la más baja en los últimos 15 años y muy alejada del objetivo de la OMS y la UE, establecido en un 75\%, así como de países de nuestro entorno (Reino Unido, Alemania o Francia) (4).

No obstante, para que esto se pueda llevar a cabo es necesario una formación eficaz y una capacitación para su implementación como servicio profesional farmacéutico en la farmacia comunitaria. SEFAC, directamente o en colaboración con otras entidades y/o sociedades científicas, formaría y capacitaría certificando a aquellos profesionales sanitarios que lo requieran, acreditando así su competencia profesional. La validez de la capacitación y la certificación deberá ser revalidada periódicamente.

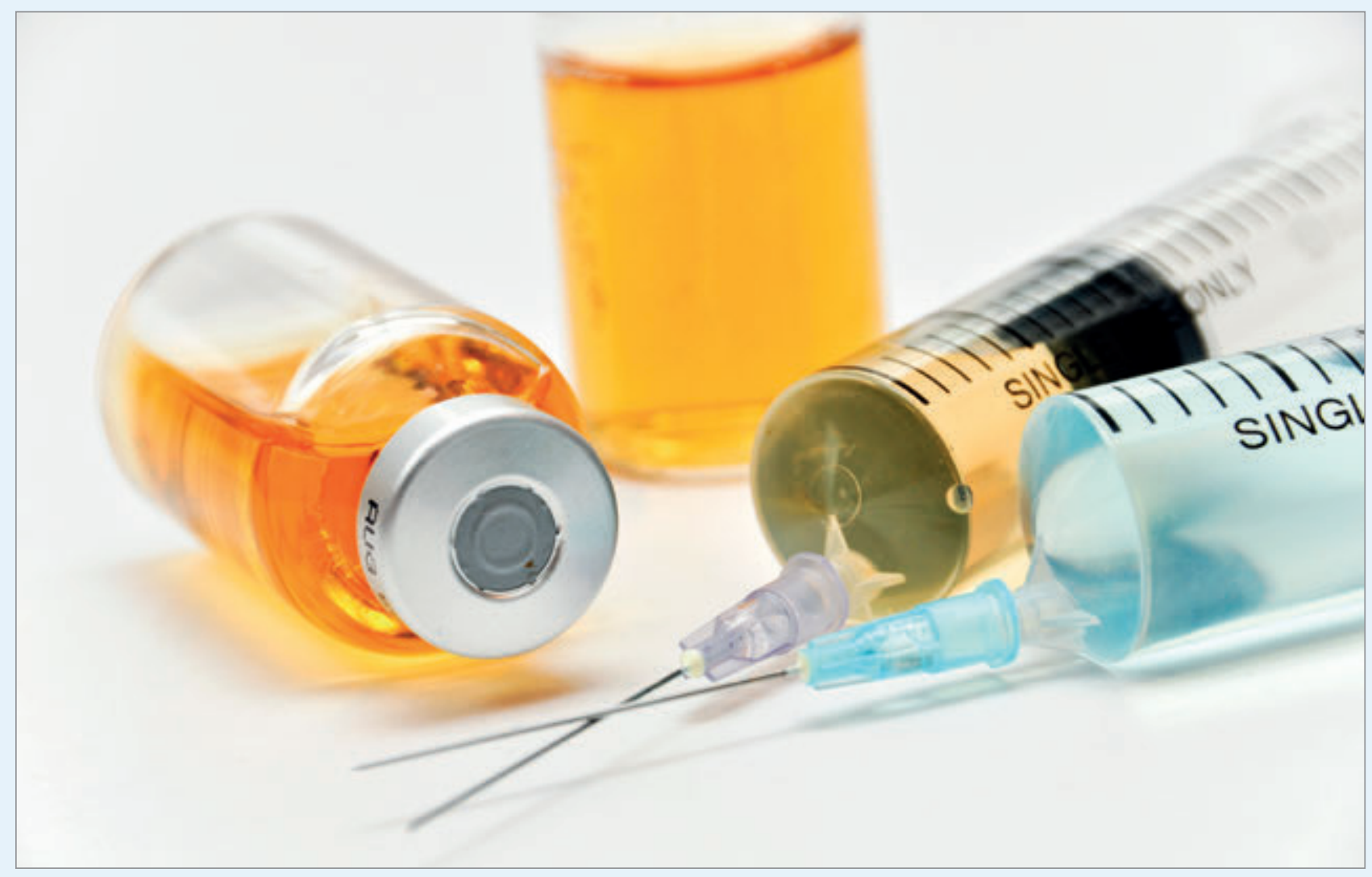


A este respecto el papel de las sociedades científicas está reconocido legalmente en la formación sanitaria especializada.

En esta línea de trabajo, SEFAC pondrá a disposición de sus socios y simpatizantes en el próximo mes de octubre el curso on line Consultas frecuentes sobre vacunas en farmacia comunitaria. Desde estas líneas os animo a realizarlo, ya que es un buen punto de partida para hacer ver al sistema sanitario que el farmacéutico comunitario juega un importante papel en la prevención de enfermedades.

La OMS estima que en la actualidad las vacunaciones contribuyen a prevenir 2,5 millones de muertes cada año a nivel mundial, lo que significa que cada 6 minutos se previenen 6 muertes en el año. Si el farmacéutico comunitario participara activamente en la prevención de enfermedades a través de la administración de vacunas desde la botica, podríamos concluir que estas cifras aumentarían (1).

\section{Referencias bibliográficas}

1. Puerta López-Cózar JL, Gil de Miguel A. Presente y futuro de la vacunología. Madrid, Mediscript, SL, Colección Dendra Médica, 2014; Prologo:46-70

2. Geriatras recomiendan la creación de un calendario de vacunas específico para mayores. Portal de actualidad y noticias de la Agencia Europa Press. Publicación digital. Fecha de publicación 25-07-2015. [consultado 29-08-2015] ]Disponible en: http://www.europapress.es/buscador.aspx?buscar=vacunacion+frente+a+la+gripe

3. Correo Farmacéutico [Internet]. García Suárez B. Vacunar en boticas mejora la inmunización. Correo Farmacéutico. 8 de junio de 2015. Disponible en: http://www.correofarmaceutico. com/2015/06/08/al-dia/profesion/gripe-abre-vacunacion-botica

4. Cobertura de vacunación. Datos estadísticos. Ministerio de Sanidad, Servicios Sociales e Igualdad [Internet]. [consultado 26-08-2015]. Disponible en: http://www.msssi.gob.es/profesionales/saludPublica/prevPromocion/vacunaciones/coberturas.htm\#decimo 